\title{
Movimientismos en perspectiva comparada: peronismo y radicalismo yrigoyenista
}

\section{César Tcach*}

Perfiles Latinoamericanos, $24(48)$

2016 | pp. 61-82

DOI: $10.18504 / \mathrm{pl} 2448-003-2016$

\section{Resumen}

Este artículo analiza el movimientismo como fórmula política y componente de la identidad de las dos principales fuerzas argentinas: el radicalismo y el peronismo. Sostiene la hipótesis de dos tipos distintos de movimientismo: uno "débil" (el radical) y otro "fuerte" (el peronista). En función de este interés centra su atención en cuatro aspectos: las culturas políticas de radicales y peronistas, los tipos de liderazgo, las fórmulas organizativas y la relación con el Estado.

\section{Abstract}

This article analyzes the movimientismo as a political formula, or the identity of the two main Argentine forces: Radicalism and Peronism. Hypothesizes two different types of movimientismo: a "weak movimientismo" (radical) and other "strong" (Peronist). Based on this comparative interest focuses on four aspects: the radical and Peronist political cultures, types of leadership, organizational forms and the relationship with the State.

Palabras claves: movimientos nacionales, partido, Estado, competencia política, definición del enemigo, liderazgos.

Keywords: National movements, party, State, competition policy, definition of the enemy, leadership.

* Profesor titular Plenario de la Universidad Nacional de Córdoba e investigador Principal del coniCET. 


\section{Introducción}

onstituye un lugar común en los estudios sobre Argentina - tanto los realizados en clave histórica como politológica - la referencia a la vocación movimientista presente en la construcción de la identidad política de radicales y peronistas. Al respecto, Tulio Halperín Donghi sostuvo con acierto que Argentina fue "un país conquistado sucesivamente por dos movimientos políticos de signo antiimperialista" (Halperín, 1994: p. 59). En coincidencia con esta afirmación, Alejandro Cattaruzza añadió que el declive del movimientismo radical coincidió con el auge del movimientismo peronista a partir de 1945 (Cattaruzza, 1997: p. 67). También en la compilación de Manuel Alcántara y Flavia Freidenberg dedicada a los partidos del Cono Sur, se hace mención destacada a la tradición movimientista de radicales y peronistas (Escudero, 2003: pp. 39-40, 71-77). Empero, estas afirmaciones — compartidas por la mayor parte de la literatura sobre el tema— descansaron más en sus similitudes — como su ambición de representar al "todo" y su sesgo antioligárquico y antiimperialista- que en la indagación de sus contrastes. Es razonable suponer que dilucidarlos y analizarlos dista de ser una tarea menor para avanzar en la comprensión de la historia argentina contemporánea.

Desde este ángulo de preocupaciones, el presente artículo tiene por objeto el estudio en clave comparativa de dos fuerzas políticas argentinas que se concibieron a sí mismas como movimientos nacionales: el radicalismo yrigoyenista (conocido también con el nombre de intransigente en las décadas de 1940 y 1950) y el peronismo, particularmente, desde su gestación hasta su derrocamiento en 1955. La clave comparativa se organiza en torno a cuatro planos de análisis: la cultura política, la fórmula organizativa (traducción institucional de la vocación movimientista), los tipos de liderazgo, y la relación con el Estado. El hilo conductor que permite asociar estas distintas dimensiones remite a las formas de construcción de la representación política en Argentina y, con mayor precisión, al peso específico del componente movimientista en la configuración de sus identidades políticas.

En relación con el campo de preocupaciones descrito, el texto se articula en cuatro secciones. En la primera se plantean precisiones conceptuales en torno al clivaje partidos-movimientos nacionales y se explicitan las variables cuya indagación permitirá reconocer la fortaleza o no de la vocación movimientista en las fuerzas políticas analizadas. Se trata de fundamentar, desde el punto de vista conceptual y metodológico, la comparación entre ambos tipos de movimientismo: el radical y el peronista. 
La segunda sección centra su interés en el análisis de la vocación movimientista en la Unión Cívica Radical (UCR), desde las formulaciones iniciales de Hipólito Yirigoyen, hasta sus expresiones tardías en la época del peronismo histórico. El análisis pone de relieve las fisuras en el consenso interno partidario - lo que impidió uniformar la cultura política radical en torno a la idea de movimiento-, las limitaciones de su liderazgo, la reducción organizativa del movimiento al partido y la imposibilidad de pretender una identificación plena con el Estado y, al mismo tiempo, mantenerse como abanderado de los principios republicanos.

La sección tercera orienta su atención al análisis del peronismo entre 1945 y 1955, poniendo de relieve la fortaleza del liderazgo carismático de Perón, su traducción en el terreno de la organización política, la identificación entre movimiento y Estado, y el imperio de su impronta en la cultura política peronista. El estudio de estos aspectos ofrece evidencias empíricas para distinguir — con base en las dimensiones de análisis seleccionadas - movimientos fuertes y débiles.

Finalmente, una cuarta sección — más breve y modesta — tiende un puente con el presente: plantea interrogantes y problematiza el fenómeno del movimientismo, a la luz de las transformaciones operadas en las últimas décadas por los partidos políticos.

\section{Precisiones conceptuales. Tipos de movimientismo}

Partidos políticos y movimientos nacionales expresan principios diferentes de organización política. Mientras los primeros se reconocen como "partes" de un juego político en el marco de una competencia legítima con otros actores, los segundos se conciben a sí mismos como la representación unitaria de la voluntad de la nación y del pueblo. En caso de ser gobierno, tanto unos como otros fundamentan su legitimidad de origen en el acto electoral y, por ende, en una legitimidad democrática (De Riz, 1986: pp. 686-687; Neiburg, 1988: pp. 50-51; Romero, 2004: pp. 136-138). Empero, dado que la concepción movimientista descansa en la creencia de que la propia fuerza política es la expresión totalizadora de la voluntad nacional y los valores nacionales, tiende a identificar a quienes no adhieren a sus filas como actores o individuos que defeccionan de sus deberes patrióticos (Aboy, 2001: pp. 96-97). Al establecer una frontera entre lo nacional y lo antinacional, el tipo de competencia entre los actores es proclive a ser centrífuga: se compite orientándose hacia posiciones duras e irreconciliables. Las posturas matizadas y los "apoyos críticos" tienden a ser rechazados.

Desde el punto de vista metodológico, se puede comparar la fortaleza o debilidad de los movimientismos, tomando en consideración cuatro dimensiones 
relevantes: a) la cultura política, b) las fórmulas organizativas, c) los tipos de liderazgo, d) la relación con el Estado. Con mayor detenimiento:

\section{a) La cultura política.}

Ciertamente, la política no se agota en las normas, los procesos o las instituciones, implica también el conjunto de representaciones que los diversos sectores sociales o políticos tienen acerca de los fenómenos políticos. En este punto, conviene aclarar que a partir de la década de 1980, los historiadores comenzaron a utilizar el concepto de cultura política (contribuyendo a una renovación de la historia política) en un sentido más amplio del formulado originalmente. ${ }^{1}$ $\mathrm{Al}$ hacerlo operativo, remiten no solo a valores históricamente sedimentados y transmitidos a través de la socialización, sino también a las representaciones de la realidad política, incluyendo tanto ideas como aspectos simbólicos, ritos, mitos y lecturas comunes del pasado. En esta mirada, la cultura política condiciona la acción pero no la determina (Pérez Ledesma \& Sierra, 2010: p. 39). Más específicamente y en una revisión reciente del concepto, Cecilia Schneider y Karen Avenburg destacaron la necesidad de comprender la cultura política como "la matriz de significados encarnados en símbolos, prácticas y creencias colectivas mediante los cuales las personas y las sociedades se representan las luchas por el poder" (Schneider \& Avenburg, 2015: pp. 126-127). En cualquier caso, la cultura política o las subculturas políticas de determinados sectores, trascienden la coyuntura o el acontecimiento para entroncar con fenómenos históricos de media y larga duración.

En este sentido, para conocer la fortaleza o debilidad del movimientismo en la cultura política argentina, y más específicamente, en las del peronismo y el radicalismo, se torna imperativo indagar: 1) su permanencia en el tiempo,

1 Originalmente, el concepto fue formulado en el ámbito de la ciencia política por Gabriel Almond y Sydney Verba. Utilizado por primera vez en un artículo de Almond sobre sistemas políticos comparados publicado en 1956 por la Journal of Politics, no remitía a ideas o representaciones, sino que refería a creencias que pueden ser empíricas (el estado real de la política hoy) o a valores y fines. Almond y Verba suponían, desde una mirada funcionalista, que todo sistema político descansa en una cultura política. En el contexto del debate académico de su época, eran los códigos de valores compartidos y no la elección racional la variable causal de la acción política.

Los historiadores que comenzaron a utilizar el concepto en la década de los ochenta enfrentaron problemas distintos: para los investigadores en historia política la pregunta era por qué la conducta política individual presentaba pautas colectivas; entonces centraron su atención en los valores en que fueron socializados; para estudiosos de la historia social, la pregunta era por qué situaciones sociales similares dan lugar a conductas políticas diferentes. Entonces estudiaron las representaciones simbólicas que median entre las personas y sus condiciones materiales de existencia. Incluyeron ideas, representaciones y aspectos simbólicos como expresión sintética de la cultura política: la bandera nacional, la hoz y el martillo, la boina blanca de la UCR o la marcha peronista en el caso argentino (Cabrera, 2010: pp. 19-80). 
y 2) su aceptación o no por el conjunto —o bien, grupos significativos— de radicales y peronistas.

b) Las fórmulas organizativas.

En relación a esta variable cabe indagar si la concepción movimientista se tradujo o no en la creación de organizaciones externas al partido, o su imbricación con otras ya existentes. Es decir, en la complejidad del entramado organizacional en el que descansa la fórmula movimientista. En este punto, suponemos que una mayor complejidad - cuando el movimiento incluye a sectores militares, sindicales, empresariales o al propio Estado- es indicador de una mayor fortaleza - en términos comparativos- que en aquellos casos en que la vocación movimientista no trasciende los límites de la fórmula organizativa partido.

c) Los tipos de liderazgo.

Desde este ángulo de preocupaciones, conviene examinar el tipo de liderazgo que conduce el ensayo movimientista. De acuerdo con Ángelo Panebianco, conviene distinguir el liderazgo carismático "puro" del "situacional". El primero define la identidad de la organización (los sentidos de pertenencia), los procesos de toma de decisiones y su universo simbólico. El segundo, en cambio, no habilita una identificación lineal entre líder y organización (reconoce la legitimidad de sectores internos disidentes), no resume a la propia fuerza política en el plano simbólico y los procesos de toma de decisiones son objeto de una negociación permanente (Panebianco, 1990: pp. 112-114).

d) La relación con el Estado.

Un punto clave reside en determinar las pretensiones de la fuerza política movimientista: ¿̨se identifica únicamente con la nación o también con el Estado? $\mathrm{Y}$ en este último caso, ¿qué medidas o pasos lleva adelante para concretar y plasmar esa identidad entre movimiento y Estado? Este aspecto es crucial para valorar el impacto del movimientismo sobre el sistema de partidos y el componente republicano del sistema político.

A tenor de lo expuesto, consideramos que un movimientismo fuerte es aquel que: a) está sólidamente arraigado en la subcultura de la fuerza política analizada, tanto por la masiva aceptación de sus integrantes como por su permanencia a lo largo del tiempo; $b$ ) incluye organizaciones externas al partido que amplifican sus raíces en la sociedad; c) está dotado de un liderazgo carismático puro que unifica sin fisuras relevantes la conducción política, $d$ ) se imbrica con el Estado no solo por el uso de recursos estatales sino también por su identificación 
en el plano simbólico. Por el contrario, los movimientismos débiles carecen de consenso interno entre los integrantes de la propia fuerza política, constituyen fenómenos de duración temporal más limitada, no incluyen en su entramado a organizaciones externas al partido, distan de estar cohesionados por un liderazgo carismático puro y tienen un menor potencial para mimetizarse con el Estado.

\section{El movimientismo débil: el partido radical}

En la sección correspondiente a Argentina, incluida en el libro sobre partidos políticos en América Latina coordinado por Manuel Alcántara y Flavia Freidenberg se sostiene con acierto que Hipólito Yrigoyen — presidente del país en los periodos 1916-1922 y 1928-1930—, lejos de considerar al radicalismo como un mero partido político, lo definía como un movimiento de carácter nacional (Escudero, 2003: pp. 38-39). En su obra, Mi vida y mi doctrina, Yrigoyen subrayaba: "La Unión Cívica Radical es lo reitero, finalmente, la patria misma”. Y añadía, "Movimiento de Opinión Nacional que enraíza en los orígenes de Mayo", en referencia a la deposición del virrey español y la formación de la Primera Junta de Gobierno en 1810 (Yrigoyen, 2013: p. 54). ${ }^{2}$ Más precisamente, dividía la historia argentina en tres etapas: la independentista iniciada en 1810, la constitucional a partir de 1853 y la de "reparación nacional” a partir de la fundación de la Unión Cívica Radical en 1891. De acuerdo con su mirada, el radicalismo venía a reparar la falsificación de la soberanía popular y la manipulación de los mecanismos electorales por parte del régimen conservador. Por consiguiente, su nacimiento tenía por objetivo reparar "la ofensa inferida a la nacionalidad y restablece su nombre, su espíritu y sus fuerzas" (Del Mazo, 1983: pp. 11-12). Esta búsqueda de una identidad entre nación y partido fue destacada tempranamente por Liliana De Riz en su análisis comparativo de los partidos en el Cono Sur. Al respecto, destacó que "La UCR, desde su creación, había evitado una definición explícita sobre cualquier cuestión más allá de las libertades políticas y nunca formuló un programa”. Y añadía: "Con un origen social similar al de la elite tradicional en su dirigencia y el tono popular en la maquinaria partidaria [...], este partido constitucionalista rehusó definirse como un partido más y se adscribió la representación de la Nación” (De Riz, 1986: p. 673). Entre 1909 y 1910, la polémica epistolar entre Yrigoyen y el dirigente radical Pedro Molina reflejaba claramente la modalidad

2 Este texto fue escrito en 1923, editado por la editorial partidaria Raigal en 1957, reeditada en 1981 por la editorial Leviatán y en 2013 por el Instituto Nacional Yrigoyeniano con el apoyo de la Secretaría de Cultura de la Presidencia de la Nación. 
de construcción identitaria promovida por los yrigoyenistas. En su lenguaje, la dicotomía entre la "Causa" (identificada con la UCR y la nación) y el "Régimen" (asociado a los conservadores y los intereses extranjeros) derivaba en la formación de campos cerrados que no admitían contaminaciones y tornaban heréticas las políticas de alianzas con sectores extrapartidarios (Persello, 2007: p. 37). Tras el derrocamiento de Yrigoyen por un golpe militar en 1930, los levantamientos cívico-militares promovidos por el radicalismo yrigoyenista fueron caracterizados como "patriadas" (Ciria, 1975: p. 211).

La concepción que se acaba de describir sobrevivió a la muerte de Yrigoyen en 1933, aunque distó de ser hegemónica en el interior del partido. Nueve años más tarde, Arturo Jauretche —uno de los intelectuales radicales más importantes e integrante de FORJA (Fuerza de Orientación Radical de la Joven Argentina) - escribía:

Ahora hay radicales que no se atreven a decir que la UCR no es un partido político más sino la unión civil de los argentinos para realizar la Nación por encima de las facciones del Régimen que son los partidos. Encuentran eso totalitario, olvidando en todo caso que serán los fascistas los que se han copiado de Yrigoyen. La definición era perfecta y no encuentro que haya habido nunca una fuerza revolucionaria que no fuese totalitaria, es decir, que negase totalmente a cualquier facción al constituirse ella en la Nación misma, así es totalitaria la Revolución de Mayo, la francesa y la rusa, tanto como la italiana (Jauretche, 1943: p. 11). ${ }^{3}$

Entre 1945 y 1946 — en coincidencia con la génesis del peronismo— el yrigoyenismo (por entonces autodenominado "Intransigencia") persistía en identificar identidad radical con identidad nacional. Desde su óptica, a diferencia de los políticos conservadores, epígonos del imperialismo británico, en contraste con los marxistas, adláteres de una potencia extranjera y del peronismo —al que consideraban resabio del nazismo y el fascismo-, el radicalismo expresaba la única identidad verdaderamente argentina, nacional y popular. Más aún, su rechazo a la política de alianzas se alimentaba de esta convicción: la dilución de lo radical en la mezcla con otras fuerzas (frentes antifascistas o uniones democráticas) tendía a disolver esa identidad fundante que operaba como agente constructor de lo nacional.

Esta postura no era compartida por los sectores identificados con la tradición alvearista y otros, que sin tener ese origen, se habían volcado a la lucha antifascista

3 Carta de Arturo Jauretche al Dr. José Abalos del 9 de julio de 1942. Pocos años después, Jauretche adhirió al naciente movimiento peronista, anticipando la hoja de ruta de muchos de sus correligionarios: del radicalismo al peronismo.

C. Tcach | Movimientismos en perspectiva comparada: peronismo y radicalismo yrigoyenista Perfiles Latinoamericanos, 24(48) | FLACso México | pp. 61-82 | DoI: 10.18504/pl2448-003-2016 
en la Segunda Guerra Mundial. Cabe recordar que Marcelo T. de Alvear había sucedido a Yrigoyen en la presidencia del país para el periodo 1922-1928 y había presidido el comité nacional del partido radical desde 1932 hasta su muerte diez años más tarde. Alvear se había esforzado sistemáticamente por presentar al radicalismo como un partido "liberal y democrático" (Cattaruzza, 1997: pp. 66-67). En la Convención Nacional de la UCR celebrada en diciembre de 1945, el dirigente alvearista Gregorio Topolovsky fue contundente: "La UCR no es el símbolo de la patria" puesto que esta "no tiene otros símbolos que su bandera y su escudo" (La Nación, 30-12-1945). Poco tiempo antes, el mismo convencional había sostenido "antes que radicales somos argentinos" y en idéntico sentido Silvano Santander se había encargado de subrayar que la definición conceptual de la conciencia argentina debía ser forjada por todos los partidos políticos (La Voz del Interior, 1/8-9-1945).

Desde la óptica de los sectores yrigoyenistas, intransigentes y sabattinistas, en cambio, el radicalismo no era solo el resumen de lo nacional sino "el único partido democrático del país” (Tcach, 2006: p. 38). Este razonamiento —que ignoraba los aportes democráticos de otros partidos como el Partido Socialistatenía como corolario poner de manifiesto el carácter superfluo y el riesgo de las coaliciones políticas era una suerte de aporía, encerraba una contradicción en sus propios términos. Si el radicalismo era considerado la síntesis de lo nacional y lo democrático, y en términos más crudos, el único partido democrático de la Argentina, se descalificaba al resto como pares en el juego político.

Empero, con la irrupción del peronismo en el escenario político argentino, la propensión movimientista del radicalismo tenderá a declinar. Como ha señalado Alejandro Cattaruzza:

Por primera vez un adversario, el peronismo, le disputaba casi con sus mismos argumentos, el lugar del "movimiento nacional" [...] Sin perderse por completo, los arrebatos movimientistas del radicalismo terminaron por ceder ante la imagen que hacía de la UCR un partido más entre otros y a la tradición radical se incorporó definitivamente el reconocimiento pleno de la pluralidad de representaciones políticas (Cattaruzza, 1997: pp. 67-68).

Este proceso se acentuó en los años posteriores. En 1955 los radicales participaron junto a otros sectores civiles como "una parte más" en el derrocamiento violento del presidente Perón. Formaron parte, asimismo, junto al resto del arco político antiperonista de la Junta Consultiva Nacional de los Partidos Políticos, organismo asesor de los dos primeros gobiernos posperonistas. En noviembre de 1956, la fractura de la UCR en dos partidos - Unión Cívica Radical del Pueblo (UCRP) y Unión Cívica Radical Intransigente (UCRI) — marcó el punto final 
a las pretensiones movimientistas. Estas solo reaparecieron fugazmente durante la fase inicial del gobierno de Raúl Alfonsín. En aquellos momentos se hablaba del "tercer movimiento histórico": el primero había sido el radicalismo, el segundo el peronismo y el tercero era el que estaba en construcción liderado por el presidente de la nación.

$\mathrm{Al}$ tenor de las consideraciones precedentes, es posible afirmar que en una mirada de larga duración, la vocación movimientista fue un componente importante de la cultura política radical en la primera mitad del siglo xx. Pero su fortaleza estuvo minada desde adentro por sectores y dirigentes que cuestionaron esa identificación. Bien podría pensarse que esa retórica movimientista era funcional al presidencialismo exacerbado de Hipólito Yrigoyen: permitía legitimar la devaluación del Parlamento como ámbito de deliberación y toma de decisiones (Romero, 2004: p. 76). Pero el líder radical fue incapaz de obtener el consenso de sus correligionarios. Como vimos, otros sectores y dirigentes del partido radical, desde Pedro Molina hasta Marcelo T. de Alvear o Silvano Santander, tendieron a concebirlo en clave liberal democrática. Es decir, como una parte de un sistema de partidos orgánicos, permanentes, nacionales y organizados con base en reglas compartidas, por consiguiente, orientados a su institucionalización en el marco de un sistema plural de partidos políticos. En contraste con el peronismo, el radicalismo careció de una jefatura indiscutible y el movimientismo distó de imponerse como la representación excluyente que los radicales tenían de sí mismos. El sentido de la identidad radical estuvo siempre en disputa.

Desde el punto de vista organizativo, la vocación movimientista del radicalismo no se tradujo en la creación o reconfiguración de instituciones externas al partido. No contó con sindicatos, centrales empresarias o un Ejército que pudieran identificarse o servir de sostén a la ambición de una "patria radical". En rigor, se trataba de un partido que procuraba ser percibido como movimiento nacional, pero con base en la fórmula organizativa partido. Un partido cuyas concepciones estaban en consonancia con los presupuestos del liberalismo político: criterios representativos (convenciones nacionales, provinciales, departamentales, voto directo y secreto para elegir autoridades partidarias y candidatos a cargos electivos, etc.) y búsqueda (aunque en la práctica fuesen con frecuencia procesos tormentosos no exentos de escisiones) de resolución institucional de los conflictos. En otras palabras, el movimientismo radical no se tradujo en un formato — en el sentido sartoriano del término (Sartori, 1987) — movimientista. Su unidad organizativa básica fue el propio partido.

A los tres factores señalados — una cultura política que albergaba distintas miradas sobre la propia identidad, un liderazgo impotente para imponer una única representación del partido, y una fórmula organizativa limitada al 
partido- se añade un cuarto elemento que operaba en detrimento de la potencia del movimientismo radical. Este se identificaba con la nación pero no con el Estado. En este punto se diferenció claramente, por ejemplo, de la Iglesia católica que, al tiempo que reclamaba para sí el monopolio de la identidad nacional, buscaba y legitimaba a partir de un razonamiento análogo la confesionalización del Estado, sobre todo, a partir de la década de 1930 (Zanatta: 1996). Los radicales buscaban poblar el Estado de sus correligionarios, es verdad, pero en la misma medida que lo hicieron los conservadores y otras fracciones políticas sustentadas en lógicas clientelares; no como un imperativo derivado de la propensión movimientista. Decir que se trataba de un tipo de movimientismo que se identificaba con la nación pero no con el Estado dista de ser un dato menor. Permite explicar la paradoja que le permitió presentarse al mismo tiempo como el abanderado de las libertades públicas y el pluralismo político.

En resumen, el movimientismo en clave radical descansó en una articulación partidaria ciudadana, se identificó con la nación pero no lo hizo extensivo al Estado y, en consecuencia, sus efectos sobre las prácticas políticas con respecto a las libertades públicas y al ejercicio de la competencia política fueron moderados. Sirvió, sobre todo, para cohesionar a los propios y legitimar la renuencia a la negociación con otros actores políticos. Pero cabe destacar también que estuvieron fuertemente condicionadas por los presupuestos que le dieron sentido en el imaginario de muchos argentinos: ser el partido que expresaba más consecuentemente la defensa de la ciudadanía política. Desde esta óptica afirmamos que el movimientismo radical fue una vocación doblemente inconsecuente: con su deseo de abarcar la totalidad societal (a partir de un partido fuertemente marcado por el liberalismo político), y con la propia lógica de la democracia del que se consideraba su adalid.

\section{El movimientismo fuerte: el peronismo}

El 17 de octubre de 1950, cuando Perón dio a conocer desde el balcón de la Casa Rosada las "veinte verdades" del justicialismo, la palabra Movimiento fue mencionada en dos oportunidades: en la verdad tercera sostenía que el justicialista trabajaba para el Movimiento y en la octava subraya que en su escala de valores primero estaba la Patria, después el Movimiento y luego los hombres (www.pj.org.ar). Este lugar central de la idea movimientista en la cultura política peronista se reflejó en los estatutos partidarios de 1954 en un cambio de denominación: el de Partido Peronista por el de Movimiento Peronista (Levitsky, 2005: p. 50). En el análisis de su desarrollo, Steven Levitsky señala dos fases, una primera marcada por la centralización en el líder carismático y el Estado, 
y una posterior a la caída de Perón en 1955 caracterizada por mayores márgenes de autonomía de un conjunto de agrupaciones que se reclamaban como parte de un movimiento pero carecían de una conducción nacional unificada y coherente (Levitsky, 2005: p. 53). Centraré mi atención en el periodo de génesis y consolidación del peronismo (1945-1955) por dos motivos. Por su utilidad para efectos del análisis comparativo con el movimientismo radical, que inició su declinación en esa misma época; y por definir huellas de larga duración en la identidad y conformación del peronismo. ${ }^{4}$ Con el fin de ordenar la argumentación, distinguiré tres aspectos cruciales:

\section{a) La relación partido-Estado.}

Hace muchos años Walter Little sostuvo que el peronismo histórico intentó constituir un State Party (Little, 1973: p. 658). Sin entrar en la discusión acerca de los márgenes de autonomía de sus subunidades organizativas mínimas —las Unidades Básicas - lo cierto es que en contraste con el radical, el movimientismo peronista tuvo una traducción en el plano de su fórmula institucional que involucraba al Estado: a partir de 1952 sus máximas autoridades coincidían — valga la redundancia — con las máximas autoridades del Estado peronista, en el orden nacional, provincial y municipal. El Comando Estratégico estaba encabezado por el presidente de la nación y sus ministros del Interior y de Asuntos Políticos, el Comando Táctico era presidido por el gobernador de cada provincia (su sede era la Casa de Gobierno) y los Subcomandos Tácticos tenían como máxima autoridad a los intendentes o comisionados municipales (Tcach, 2006: p. 202). Los lugares físicos donde se reunían estos comandos de dirección eran estatales: la Casa Rosada en Buenos Aires, las casas de gobierno en las respectivas provincias y las sedes municipales.

b) La creación o cooptación de asociaciones externas al partido y de instituciones estatales. Ciertamente, el movimientismo peronista descansó en una articulación orgánica mucho más amplia que la del propio partido: incluyó al gobierno, sindicatos oficialistas, las organizaciones empresariales y las Fuerzas Armadas. El partido era un elemento más — la herramienta electoral — dentro de una estructura más amplia que incluía una central obrera única (Confederación General del Trabajo, la CGT) sin representación de las minorías en su

4 De acuerdo con Ángelo Panebianco, "la manera en que se reparten las cartas, así como los resultados de las diversas partidas que se juegan en la fase originaria de una organización y en los momentos inmediatamente posteriores, continúan, en muchísimos casos, condicionando la vida de la organización a decenios de distancia”. Esa combinación de factores que dejan su huella en el largo plazo, es conceptualizada como "modelo orginario" (Panebianco, 1990: pp. 17-108). 
dirección ni en la de los sindicatos adheridos (Torre,1990: pp. 226-250), una organización empresarial vinculada al gobierno, compuesta por empresarios nacionales que producían para el mercado interno, la Confederación General Económica (CGE); ${ }^{5}$ y las Fuerzas Armadas, a las que se alineó en torno a la doctrina peronista: se convirtió en materia obligatoria de enseñanza en el Colegio Militar de la Nación y en la Escuela Superior de Guerra (Rouquié, 1986: p. 94). En el plano simbólico se expresó —entre otras manifestaciones- en la designación de nuevos barrios militares con el nombre del presidente en ejercicio o la multiplicación de bustos de Eva Perón en las puertas de guarniciones militares y otros ámbitos castrenses (Tcach, 2006: p. 249). ${ }^{6}$

Las prácticas políticas que alimentaba este tipo de articulación movimientista-semicorporativa y estatalista estaban en consonancia con el ideal - expuesto por el propio Perón - de una comunidad organizada, donde la unidad y la cohesión primasen sobre la diversidad y el pluralismo. A diferencia del movimientismo radical, su vocación hegemónica descansaba en una red de actores colectivos y organizados, así como en indisimulable impronta estatal.

\section{c) El liderazgo carismático de Perón.}

En el terreno de la dinámica interna del movimiento nacional justicialista, la conducción de Perón lejos de ser mera repetición de pautas caudillistas, tuvo las características de un liderazgo carismático puro. ${ }^{7}$ Entre 1947 y 1955, el Partido Peronista estuvo intervenido en todas las provincias del país. Su dirección -el Consejo Superior Nacional con sede en Buenos Aires- implementaba sus directrices a través de "interventores" que, en la generalidad de los casos, pertenecían a los bloques justicialistas de diputados y senadores nacionales. De este modo, la presencia de interventores, lejos de ser una anomalía en su funcionamiento político interno o ser producto de urgencias meramente coyunturales, constituyó una fórmula normal y típica que garantizaban la concentración funcional de la autoridad en el propio Perón. En su calidad de delegados del Consejo Superior, los interventores constituyeron la máxima instancia de soberanía interna en el plano local y sus atribuciones — por ejemplo,

5 De acuerdo con el meticuloso estudio de Brennan y Rougier, en 1955 "la presión estatal sobre la CGE estaba en aumento y no es improbable que el golpe de Estado haya salvado a la CGE de la total absorción por parte del gobierno" (Brennan \& Rougier, 2013: p. 132).

6 Como dato ilustrativo: en 1954 el barrio militar de una de las principales guarniciones aéreas del país, la de Córdoba, fue bautizada con el nombre de Presidente Perón.

7 Utilizo el concepto de liderazgo carismático puro en el sentido otorgado por Ángelo Panebianco: el líder es considerado como el creador e intérprete indiscutido tanto en el plano ideológico como simbólico: el partido no tiene una existencia autónoma del líder y este es capaz de controlar el conjunto de las zonas de incertidumbre, es decir, de los recursos del poder organizativo (Panebianco, 1990: pp. 111-114). 
en la nominación de candidatos a cargos electivos- eran incluso superiores a la de las propias convenciones de distrito. ${ }^{8}$ Este manejo de los recursos del poder organizativo por parte de Perón, se asociaba a una concepción que lo convertía no solo en el representante de un movimiento sino en su encarnación providencial. En la cultura política peronista era concebido como la expresión viva del movimiento y en su figura se resumía la propia identidad de ese espacio político. Existe abundante evidencia empírica al respecto. Los propios Estatutos del Partido Peronista — del año 1954 - le confirieron autoridad para modificar o declarar nulas las decisiones partidarias y, más aún, para "inspeccionar, intervenir y reemplazar" a sus dirigentes (Levitsky, 2005: p. 49). En la Conferencia de Gobernadores de 1950, el contraalmirante Alberto Teisaire — unos años después vicepresidente del país - lo expresaba de modo sencillo y contundente: "En el partido peronista uno solo manda y uno solo es el que tiene los votos [...] el general Perón es quien dirige y cambia el camino" (La Voz del Interior, 24-6-1950). Abel Barrionuevo, interventor en el Partido Peronista de Córdoba, lo describió con mirada de futuro: "Aspiramos a que cuando la historia hable de Perón, diga solamente que a su lado hubo un partido formado por hombres de los que sólo sabemos le seguían fanáticamente" (Córdoba, 8-9-1953). La articulación movimientista del peronismo descansaba en una concepción comunitaria-organicista de la política y de la sociedad concebida como una comunidad organizada. ${ }^{9}$ Ella no condujo a la eliminación de los conflictos endógenos, pero distó de carecer de efectos de sentido sobre las prácticas políticas y organizativas del amplio espacio liderado por Perón. No hubo gulag, pero sus efectos de disciplinamiento fueron insoslayables (Macor \& Tcach, 2013: pp. 10-12).

Finalmente, y vinculado a los aspectos precedentes, las relaciones del movimiento peronista con el arco opositor estuvieron signadas por la ausencia de

8 La elección de legisladores nacionales como interventores en los distintos distritos no era casual. Dado que residían una parte de la semana en Buenos Aires — sede del Parlamento nacional—, Perón podía ejercer un control directo sobre ellos (Tcach, 2006: pp. 164-166).

9 Esta concepción remite a una metáfora biológica: al ideal de un organismo en el que cada parte tiene una función, y la integración se funda en la primacía de la unidad sobre el conflicto. Al respecto, Perón señalaba en su obra La Comunidad Organizada: " la sociedad política como un cuerpo humano regido por las leyes inalterables de la armonía: corazón, aparato digestivo, músculo, voluntad, cerebro, son en el símil de Platón, órganos felizmente trasladados por sus funciones y sus fines a la biología colectiva: un Estado de justicia, en donde cada clase ejercite sus funciones en servicio del todo, se aplique a su virtud especial, sea educada de conformidad con su destino y sirva a la armonía del todo. El Todo, con una proposición central de justicia, con una ley de armonía, la del cuerpo humano, predominando sobre las singularidades" (Perón, 2006: p. 33). Asimismo, su ideal de "perfección orgánica" hasta en "la última célula partidaria", estaba muy presente en sus clases en la Escuela Superior Peronista (Perón, 2009: pp. 49-50). 
juegos políticos cooperativos. La frontera política del movimiento nacional dejaba extramuros al resto de los actores políticos partidarios. En consonancia con ello, nuevas normativas y leyes se orientaron a constreñir la competencia política. Conviene a mi argumentación destacar tres acontecimientos que son ilustrativos al respecto. El estatuto de los partidos políticos (1949), la ley electoral de 1951 y la definición por ley de una doctrina nacional (1952):

- El estatuto de los partidos políticos de 1949. Que implicaba un veto legal a dos de las tácticas que podía emplear la oposición: la abstención y la coalición electoral. El artículo 5 establecía que las coaliciones solo serían reconocidas y estarían en condiciones de presentarse a elecciones si registraban con tres ańos de anterioridad a los comicios, su nombre, plataforma y estatutos. Asimismo, los partidos que promoviesen la abstención electoral serían disueltos (incisos "b" y "d"). Esta ley, aprobada con premura y sin despacho de comisión en el Parlamento, fue tema editorial del diario $L a$ Nación: impide "la abstención electoral y las alianzas, procedimientos que en todos los países democráticos se han practicado siempre como incuestionables derechos". Si "no presentan candidatos en una elección nacional o no concurren al acto electoral", si pactan "fusión, alianza, unión o coalición con otro partido político serán declarados disueltos y no podrán volver a constituirse sino con plazo de tres años" (La Nación, 26-10-1949).

- La ley electoral de 1951. Dividía el mapa electoral en circunscripciones que podían unir a dos o más departamentos en el interior de cada provincia argentina y rediseñar las unidades electorales en las capitales de cada una de ellas mediante la unión total o parcial de sus subunidades (seccionales). Dado que los criterios de fusión/separación eran eminentemente políticos, la dirigencia opositora identificó el procedimiento con el conocido en Estados Unidos con el nombre de "Gerrymander" (La Nación, 15-9-1951; Los Principios, 9-12-1951; Córdoba, 11-9-1951/10-10-1951).

— En 1952, a través de la ley 14.184, se definió como "doctrina nacional adoptada por el pueblo argentino, la doctrina Peronista o Justicialista, que tiene como finalidad suprema alcanzar la felicidad del pueblo y la grandeza de la nación" (Del Barco, 1983: p. 136; Antoni, 1954). Cabe detenerse en ambos términos. La "doctrina", desde la mirada de Perón, no se reducía a un conjunto de principios que debían ser enseñados. Suponía algo más profundo, apuntaba — como él mismo explicaba en la Escuela Superior Peronista- a "formar apóstoles de nuestra doctrina. Por esa razón yo no digo enseñar la doctrina: digo inculcar la doctrina" (Perón, 2009: p. 15). La idea de una 
doctrina "nacional" única enlazaba de modo directo con la relación oficialismo-oposición: en este punto cabe recordar que ya en la Conferencia de Gobernadores de 1949, Perón había expresado que conservadores, radicales, socialistas y comunistas eran "fuerzas alentadas desde afuera" del país y carentes de "ideales nacionales" (La Voz del Interior, 26-7-1949). En el orden simbólico latía la idea de una ruptura fundacional: el triunfo de Perón en las elecciones de 1946 habría puesto final a la era de dominación extranjera.

En correlación con los aspectos precedentes, el radicalismo y otros sectores políticos tendieron a desarrollar una oposición desleal —en el sentido definido por Juan Linz (Linz, 1989: pp. 57-65) orientado a derrocar por medio de la violencia y en cooperación con sectores militares y eclesiásticos- al gobierno electo en 1946 y reelecto en 1951. Prueba de ello fue su participación en el golpe cívico militar conocido con el nombre de "Revolución Libertadora" en septiembre de 1955 (Spinelli, 2005: pp. 21-51; Capellupo, 2005: pp. 175-187; Sáenz, 2007: pp. 57-80).

\section{Interrogantes desde el presente: en torno a la viabilidad del movimientismo}

¿Pueden los movimientos nacional-populares sobrevivir a las tendencias predominantes en la política contemporánea? En la década de 1960, el politólogo alemán Otto Kichheimer puso de manifiesto el paulatino ocaso de los partidos de masas que habían alumbrado la construcción del Estado de bienestar en la Europa de la segunda posguerra mundial. En relación a este tema, explicó y defendió la idea del Catch All Party: los partidos habrían perdido intensidad ideológica, subordinado sus ideales de más largo aliento a las necesidades prácticas de resolución de problemas que imponía cada coyuntura, ya no tenían como base social a una clase y fracciones de clase determinadas sino que se dirigían a un electorado mucho más amplio (Kirchheimer, 1980: pp. 328-347). Ciertamente, en aras de la maximización de los votos se tendió a minimizar sus principios (Offe, 1988: p. 63).

La lógica atrapatodo —o "pillatutto" como dicen los italianos— se sitúa en las antípodas tanto de los movimientos sociales como de los movimientos nacionales. Los primeros aspiran a expresar partes de la sociedad. Los segundos pretenden representar el todo (pueblo, nación). La lógica atrapatodo, empero, dista de cobijarse en las distinciones que se parapetan y embanderan en los movimientos sociales y carece de la frontera política y la definición del enemigo presente en la forja de los movimientos nacionales. Dos elementos decisivos y 
consustanciales a esta lógica estimulan la versatilidad de los dirigentes políticos: el imperio de la imagen — que Giovanni Sartori identificó con la videopolítica (Sartori, 1988) — que tiende a vaciar de contenido al mensaje político (el videolíder no transmite un mensaje sino que él mismo es el mensaje) y el papel decisivo de las encuestas de opinión, rutinariamente encargadas por políticos y partidos: las intenciones reales y los proyectos no solo pasan por el tamiz de su veredicto, sino que pueden generar tanto la metamorfosis de los objetivos perseguidos como su ocultamiento.

En la definición de la agenda política, los temas elegidos deben ser los suficientemente amplios y genéricos como para no herir a nadie: la seguridad, la educación, el desarrollo, la prosperidad, la paz. En el universo catch all no hay lugar para los movimientos nacionales que dividen binariamente el campo político y delimitan un campo de exclusión a partir de la definición del enemigo. Tampoco para algún tipo de participación política de masas en clave movilizacionista, mucho menos supone la presencia de élites anti statu quo (Di Tella, 1974: pp. 76-82). Asimismo, no hay espacio para liderazgos carismáticos trascendentes (así, en un ejercicio de ficción, sería una suerte de proeza imaginativa evocar un Perón que consultase a sus encuestadores antes de tomar una decisión). Es verdad que, en el caso argentino, el presidencialismo y la centralización de recursos en el Estado nacional favorecen la orientación fundacional de los líderes, pero también lo es que sus carismas son situacionales (Cheresky, 2007; Cheresky $\&$ Annunziata, 2012). No obstante, el fracaso de esas experiencias puede generar reactivamente, tanto partidos antisistémicos como movimientos nacional-populares capaces de hurgar y asumir parte de la caja de reivindicaciones sociales despreciadas por una forma de hacer política que soslaya la distancia entre bases sociales de apoyo (raíces) y rentabilidad electoral de corto plazo (marketing).

A partir de 1983, es posible constatar que la tendencia general de las fuerzas políticas argentinas —incluidos radicalismo y peronismo - se orientó hacia un formato de partidos electorales marcados — como en su momento seńalaron Marcelo Cavarozzi y Juan Manuel Abal Medina (h) — por una baja densidad organizacional, una menor intensidad ideológica y un mayor énfasis en obtener victorias electorales que en representar intereses sociales (Cavarozzi \& Abal Medina (h), 2001: p. 531). A estos tres rasgos se les podrían añadir otros dos: los amplios márgenes de autonomía de líderes locales en detrimento de las decisiones orgánicas nacionales $-\mathrm{y}$ en consecuencia, una ostensible fragilidad de los niveles de institucionalización partidaria ${ }^{10}$ - y mayor peso de los cargos

10 De acuerdo con Ángelo Panebianco, la institucionalización organizativa puede ser medida en dos dimensiones: el grado de autonomía de la organización con respecto a factores externos y el grado de interdependencia entre las distintas partes de la organización. Mientras mayor sea la autonomía y la co- 
públicos — parlamentarios y ejecutivos— sobre los partidarios. En relación a este ángulo de preocupaciones, los estudios de Gerardo Scherlis ponen de relieve para el caso argentino la configuración de una fórmula organizativa que resume las transformaciones recientes: el partido estatal estratárquico de redes (Scherlis, 2009: pp. 131-158). En congruencia con los aportes de Richard Katz y Peter Mair, se trata de un partido de funcionarios cuya existencia no se concibe fuera del Estado (Katz-Mair, 1994: pp. 7-12; Mair, 2015: pp. 23-78); ${ }^{11}$ pero la fórmula es complejizada por dos tipos de redes estatales: las "profesionales" orientadas a la gestión pública en posiciones de gobierno, y las "territoriales", construidas en función de fines asistenciales en el marco de intercambios clientelares. Constituyen instancias de intermediación con respecto a bienes y servicios entre líderes políticos que ocupan altos cargos estatales (gobernadores e intendentes, principalmente) y la población. Ambos tipos de redes tienen en la cima a un líder que opera como epicentro y está provisto de un amplio margen de autonomía con respecto a sus seguidores. Empero, ese liderazgo nacional está condicionado por lo que Scherlis, siguiendo a Kenneth Carty, denominó el imperativo estratárquico: la necesidad de reconocer la autonomía de los actores que se desempeñan en los distintos niveles (provincial, municipal, local) donde se desarrolla la competencia política para establecer sus propias estrategias (políticas de alianzas, prioridades, formas de articulación internas) de cara al objetivo principal: el triunfo electoral (Scherlis, 2009: pp. 152-153). El principio de conducción nacional — que descansaba en organismos colegiados como los comités o juntas nacionales de cada partido- o bien en un líder carismático con capacidad para imponer decisiones en los pleitos locales o provinciales, pasó a formar parte del baúl de los recuerdos. Así, los bajos niveles de institucionalización implican una estructura flexible provista de una fuerte capacidad de adaptación a los cambios necesarios para alcanzar o conservar el poder en los distintos niveles del Estado. Su contrapartida es la "desnacionalización” del sistema de partidos, es decir, la progresiva diferenciación entre vida política nacional, provincial y municipal con la consiguiente heterogeneidad de fuerzas políticas y liderazgos en diversas partes del país (Varetto, 2014: p. 567).

A la luz de estas transformaciones organizativas —que suponen una clara devaluación de los componentes identitarios e ideológicos-, la emergencia de un movimiento nacional exitoso, es decir, perdurable en el tiempo (al estilo

herencia estructural interna, mayor será el nivel de institucionalización alcanzado (Panebianco, 1990: pp. 114-125).

11 En el análisis del peronismo kirchnerista, Scherlis concluyó que "en el nivel nacional el partido como conjunto de redes de funcionarios no es sólo la cara dominante del partido [...] sino en gran medida la única existente" (Scherlis, 2012: p. 72). 
del yrigoyenismo radical y el peronismo histórico), es poco viable. Tanto en la versión débil de los radicales, como en las más fuerte de los peronistas, el movimientismo del siglo XXI presume más de lo que puede ser y ofrecer.

\section{Reflexiones finales}

Una pregunta subyace al hilo conductor de este texto: ¿cómo se construyó la representación política en Argentina? La forma organizativa partido ha sido una de ellas, pero a diferencia de Chile y Uruguay, distó — a lo largo del siglo $\mathrm{xx}$ - de ser la predominante. Ciertamente, una de las claves residió en la primacía de la mediación corporativa sobre la partidaria (Ansaldi, 1994: pp. 115-135). Si los sectores dominantes y sus asociaciones sectoriales fueron incapaces de institucionalizar las alianzas de partidos conservadores provinciales en un gran partido nacional competitivo y perdurable e intentaron vehiculizar sus intereses a través de gobiernos militares amigos, el movimiento obrero encontró en los sindicatos - y no en partidos obreros- el instrumento más formidable para hacer sentir su peso en la arena política (Di Tella, 2003: pp. 40-63). La sociedad civil fue capaz de construir un amplio tejido de asociaciones, se saturó de mediaciones organizativas, pero fue renuente a hacer de la fórmula partido la llave maestra de sus procesos de toma de decisiones políticas y resolución de conflictos. Sin embargo, este fenómeno fue también el producto de la modalidad movimientista de construcción de las principales identidades políticas argentinas: peronismo y radicalismo yrigoyenista o intransigente. Así, se convirtió en un lugar común la evocación de los grandes movimientos nacionales y populares que recorrieron la historia argentina a partir de una memoria que los homologa, al privilegiar en su óptica, el enfrentamiento con enemigos comunes: la oligarquía y el imperialismo, expresados ambos en términos genéricos.

Empero, como hemos visto, un ejercicio de análisis comparado permite constatar diferencias significativas entre uno y otro. El movimientismo peronista fue forjado a partir del Estado — del control de las instituciones estatales - y supuso la creación o cooptación de instituciones externas al partido. El radical, en cambio, edificado en el campo de la oposición al régimen conservador, se recostó exclusivamente sobre la fórmula organizativa partido. El primero se identificó con el Estado e incluso pretendió estatalizar por ley su propia doctrina. El segundo limitó sus pretensiones a una identificación genérica con la "patria" o la nación.

En tercer lugar, el movimientismo peronista contó — durante el periodo del peronismo histórico (1945-1955) — con un liderazgo carismático puro —en 
la acepción ya mencionada de Ángelo Panebianco- que permitió cohesionar sin fisuras al conjunto de sus partidarios. El liderazgo radical, en cambio, fue incapaz de cohesionar tras la concepción movimientista al conjunto del partido. En tensión con tendencias internas que se reclamaban liberal democráticas distó de ser unánimemente aceptada en el universo radical. Los liderazgos radicales — de Yrigoyen a Sabattini- fueron carismáticos, pero no lo suficientes como para consolidar su hegemonía — en el sentido de dirección moral e intelectual - en el interior mismo de su propio partido. Hubo siempre sectores antimovimientistas en el interior del partido radical. En contraste con la conducción del Partido Justicialista por Perón entre 1947 y 1955, la distribución de los recursos de poder internos — las "zonas de incertidumbre" en términos de sociología de la organización (Panebianco, 1990: pp. 83-89)— estuvo dispersa en consonancia con la estructura federal del partido y la existencia de canales institucionales para el procesamiento de conflictos internos. Así, líderes regionales y provinciales construyeron sus propias bases de poder. $\mathrm{Ni}$ el radicalismo tuvo una jefatura indiscutible ni el movimientismo se impuso como único criterio. El sentido de la identidad radical estuvo siempre en disputa. A ello cabe añadir que, tras la caída de Perón en 1955, las divisiones del campo antiperonista hicieron inviable la cristalización orgánica del antiperonismo como una suerte de movimiento nacional alternativo con eje en el radicalismo y las Fuerzas Armadas (Spinelli: 2005). Este conjunto de razones que se relacionan con la intensidad de la cultura política movimientista, sus traducciones organizacionales, tipos de liderazgo y vínculos con el Estado, permiten afirmar que, en términos comparativos, el movimientismo peronista ha sido históricamente más fuerte y de efectos de más largo plazo que el formulado por la Unión Cívica Radical.

\section{Referencias}

Aboy Carles, G. (2013, junio).El radicalismo yrigoyenista y el proceso de nacionalización del espacio político. Una interpretación a través de los usos del concepto de hegemonía. Identidades. Revista del Instituto de Estudios Sociales y Politicos de la Patagonia, 3(4).

Aboy Carles, G. (2001). Las dos fronteras de la democracia argentina. La reformulación de las identidades politicas de Alfonsin a Menem. Rosario: Homo Sapiens.

Ansaldi, W. (1994). Mediaciones políticas y construcción de la democracia argentina. Estudios, (3), 115-135. 
Cabrera, M. Á. (2010). La investigación histórica y el concepto de cultura política. En Pérez Ledesma, M. \& Sierra, M. (Eds.). Culturas politicas: teoría e historia. Zaragoza: Institución Fernando el Católico/csic.

Calvo, E. \& Escolar, M. (2005). La nueva política de partidos en la Argentina. Buenos Aires: Prometeo.

Capeluppo, R. (2005). 1955. "Revolución» en Córdoba. Crónica de una cruzada civico militar polémica. Córdoba: El Emporio Ediciones.

Cattaruzza, A. (1997). Alvear, Buenos Aires: Fondo de Cultura Económica.

Cavarozzi, M. \& Abal Medina, J. M. (h) (2001). Partidos Políticos en América Latina. En Di Tella, T. Diccionario de ciencias sociales y politicas. Buenos Aires: Emecé.

Cheresky, I. (2007). La politica después de los partidos. Buenos Aires: Prometeo.

Cheresky, I. \& Annunziata, R. (2012). Sin programa, sin promesa. Liderazgos y procesos electorales en Argentina. Buenos Aires: Prometeo.

Ciria, A. (1975). Partidos y Poder en la Argentina Moderna (1930-1946). Buenos Aires: Ediciones de la Flor.

Del Mazo, G. (1983). El radicalismo. Ensayo sobre su historia y doctrina. Córdoba: Suquía.

De Riz, L. (1986). Política y partidos. Ejercicio de análisis comparado: Argentina, Chile, Brasil y Uruguay. Desarrollo Económico, 25(100), 659-684.

Di Tella, T. (2003). Perón y los sindicatos. Buenos Aires: Ariel.

Di Tella, T. (1974). Clases sociales y estructuras politicas. Buenos Aires: Paidós.

Escudero, L. (2003). Argentina. En Alcántara, M. \& Freidenberg, F. (Eds.). Partidos políticos de América Latina. Cono Sur. México: FCE/IFE.

Jauretche, A. (1943). Radicalismo y Nacionalismo. Buenos Aires: Publicaciones de F.O.R.J.A.

Katz, R. \& Mair, P. (2007). La supremacía del partido en las instituciones públicas: el cambio organizativo de los partidos en las democracias contemporáneas. En Montero, J., Gunther, R. \& Linz, J. (Eds.). Partidos políticos. Viejos conceptos y nuevos retos. Madrid: Trotta.

Katz, R. \& Mair, P. (1994). How Parties Organize. Change and Adaption in Party Organizations in Western Democracies. Londres: Sage. 
Kirchheimer, O. (1980). El camino hacia el partido de todo el mundo. En Lenk, K. \& Neumann, F. Teoría y sociología críticas de los partidos politicos. Barcelona: Anagrama.

Levitsky, S. (2005). La transformación del justicialismo. Del partido sindical al partido clientelar (1983-1999). Buenos Aires: Siglo XXI.

Little, W. (1973). Party and State in Peronist Argentina 1945-1955. Hispanic American Historical Review, 3(53), 644-662.

Macor, D. \& Tcach, C. (Eds.). (2013). La invención del peronismo en el interior del país, tomo 2. Santa Fe: Universidad Nacional del Litoral.

Mair, P. (2015). Partidos, sistemas de partidos y democracia. Buenos Aires: Eudeba.

Mair, P. ( 2007). ¿¿Gobernar el vacío? New Left Review, 142(1), 22-46.

Neiburg, F. (1988). Los intelectuales y la invención del peronismo. Madrid-Buenos Aires: Alianza Editorial.

Offe, C. (1988). Partidos politicos y nuevos movimientos sociales. Madrid: Sistema.

Panebianco, Á. (1990). Modelos de partido. Madrid: Alianza Editorial.

Pérez Ledesma, M. \& Sierra, M. (Eds.). (2010). Culturas politicas: teoría e historia. Zaragoza: Institución Fernando el Católico/Consejo Superior de Investigaciones Científicas.

Perón, J. D. (2009). Conducción política. Buenos Aires: Punto de Encuentro.

Perón, J. D. (2006). La comunidad organizada. Buenos Aires: Instituto Nacional "Juan Domingo Perón” de Estudios e Investigaciones Históricas, Sociales y Políticas.

Persello, A. (2007). Historia del radicalismo. Buenos Aires: Edhasa.

Romero, L. A. (2004). Sociedad democrática y política democrática en la Argentina del siglo XX. Buenos Aires: Universidad Nacional de Quilmes.

Rouquié, A. (1986). Poder militar y sociedad política en la Argentina, volumen II. Buenos Aires: Hyspamérica.

Sartori, G. (1998). Homo videns. La sociedad teledirigida. Buenos Aires: Taurus.

Sartori, G. (1987). Partidos y sistemas de partidos. Madrid: Alianza Universidad.

C. Tcach | Movimientismos en perspectiva comparada: peronismo y radicalismo yrigoyenista Perfiles Latinoamericanos, 24(48) | FLACso México | pp. 61-82 | DoI: 10.18504/pl2448-003-2016 
Sáenz Quesada, M. (2007). La Libertadora. Buenos Aires: Sudamericana.

Scherlis, G. (2012). Designaciones y organización partidaria: el partido de redes gubernamentales en el peronismo kirchnerista. América Latina Hoy, (62), 47-77.

Scherlis, G. (2009). El partido estatal estratárquico de redes. Apuntes sobre organización política en la era de los partidos no representativos. En Cheresky, I. (Comp.). Las urnas y la desconfianza ciudadana en la democracia argentina. Rosario: Homo Sapiens.

Shneider, C. \& Avenburg, K. (2015). Cultura política: un concepto atravesado por dos enfoques. Postdata, 20(1), 109-131.

Spinelli, M. E. (2005). Los vencedores vencidos. El antiperonismo y la "revolución libertadora". Buenos Aires: Biblos.

Tcach, C. (2006). Sabattinismo y peronismo, segunda edición. Buenos Aires: Biblos.

Torre, J. C. (1990). La vieja guardia sindical y Perón. Buenos Aires: Sudamericana.

Yrigoyen, H. (2013). Mi vida y mi doctrina. Buenos Aires: Secretaría de Cultura/Presidencia de la Nación/Instituto Nacional Yrigoyeniano.

Varetto, C. (2014). El análisis del sistema de partidos en la ciencia política argentina: aporte al estado de la cuestión y propuesta de ordenamiento. Revista SAAP, 8(2), 555-584.

Zanatta, L. (1996). Del Estado liberal a la nación católica. Buenos Aires: Universidad Nacional de Quilmes.

\section{Prensa}

La Nación (1945).

La Voz del Interior (1945, 1949, 1950).

Córdoba (1953).

Recibido el 1 de septiembre de 2014. Aceptado el 4 de diciembre de 2015. 